\title{
A SHORT HISTORY OF THE INSTITUTIONALIZATION OF INVOLUNTARY SEXUAL MUTILATION IN THE UNITED STATES
}

\author{
Frederick Hodges
}

For the past 130 years, the American medical industry has been involved in the business of removing part or all of the external sexual organs of male and female children. While the origin of sexual mutilation among prehistoric primitive peoples is a matter for theory and speculation, the origin and spread of sexual mutilation in American medical practice can be precisely documented. Seen in the proper context of the entire scope of Western history, the modern American enigma of institutionalized sexual mutilation is an historic aberration of profound significance and degree, one that could never have been predicted, and one that perhaps could not have been avoided.

\section{MODERNIZATION}

The introduction and spread of institutionalized secular sexual mutilation was a response to the tremendous social and cultural anxieties engendered by the effects of the rapid modernization and industrialization of the early decades of the Nineteenth Century. As the traditional rural agrarian-based economy was transformed into an urbanized capitalist economy, parallel changes occurred in social structure, governmental and nongovernmental institutions, demographics, and technology. One significant result of these changes was the ascendancy of the middle class to positions of economic and political power. The emergent middle class was now in a position to reinterpret social mores and redefine the individual for all of society.

As an outgrowth of the middle class, the medical establishment reflected and validated these social changes and offered treatment for the anxieties they inevitably produced, thereby laying the foundations of the modern Therapeutic State - defined by Thomas Szasz as the political order in which social controls are legitimized by the ideology of health.' For instance, in traditional agrarian society, adulthood was considered to begin at puberty. Industrialized, middle-class society extended the boundaries of childhood by more than a decade so that middle-class males could receive the specialized pro- 
fessional and academic training required by a modern industrialized society. The formidable anxieties produced by these social changes found expression in an intensified focus on childhood sexuality. In conformity with middle-class social mores, physicians theorized that childhood should be a period of complete asexuality, and, consequently, that children should be kept ignorant of sexual and reproductive information until delayed marriage. The functional significance of this change was that young people, who in previous generations had been expected to marry and commence sexual activity in early adolescence, were now expected to delay commencement of sexual activity until they were in their twenties. Young people who were unable to suppress their sexual drive were subjected not only to societal censure but to medical intervention as well.

\subsection{Degenerative Theory of Disease and the Reflex Neurosis Theory of Disease}

For reasons unrelated to the rise of the American middle-class, two French physicians in the 1820s, Xavier Bichat $(1771-1802)^{2}$ and François Broussais (1771-1838), ${ }^{3}$ developed a new model of disease - the Degenerative Theory of Disease. This model postulated that the human body was allotted a finite amount of vital energy which could either be conserved through correct living or permanently lost through wrong living. Energy depletion led to degeneration, which in turn led to the production of disease. Middle-class American physicians readily adopted this theory, but they expanded it to imply that manifestations of sexuality necessarily represented life-threatening losses of vital energy. Non-procreative use of the sexual organs, even within marriage, was viewed as dangerous. The result was the formulation of the Reflex Neurosis Theory of Disease, which postulated that the sexual organs and the erotic sensations they produced were the cause of all human disease. To validate this theory, American physicians redefined normal human sexual behavior, reproductive anatomy, and sexual function in terms of pathology.

2.1.1. Pathologization of Sexual Behavior. The pathologization of normal sexual behavior resulted in the masturbation hysteria. The term masturbation was frequently used in a generalized way to describe any sexual activity outside the context of heterosexual marital coitus for the purpose of procreation, but, in practice, a diagnosis of masturbation generally followed discovery of a child's either having sexually stimulated himself or having engaged in sexual behavior with another person. Physicians relied on specious logic to support the pathologization of sexual behavior. Clinical interviews with patients suffering from what would today be ascribed to the effects of malnutrition, overwork, venereal disease, bacterial infections, mental disorders, or tobacco and alcohol poisoning, invariably revealed a past history of masturbatory activity. On this basis, it was concluded that masturbation had brought on these pathological conditions. The inhabitants of the United States were at first reluctant to accept the theory that masturbation was harmful. Many resisted interference on the part of physicians in the private lives of their children, but the rising flood of medical journal articles that allegedly proved the harm of masturbation empowered physicians to meet this resistance with determination.

2.1.2. Pathologization of Sexual Anatomy. In order to validate the Reflex Neurosis Theory of Disease, physicians were compelled to pathologize the three distinguishing qualities of the immature juvenile foreskin, e.g., generous length, adherence to the glans, and narrowness of the preputial orifice, under the general diagnosis of phimosis. Physi- 
cians coined the term congenital phimosis to specify that the adhesion of the foreskin to the glans in infants was, in fact, a congenital birth defect. They adopted the term acquired phimosis to indicate a fictitious condition in which a previously unadhered foreskin became adhered as a result of masturbation. The term hypertrophic phimosis, or redundancy, indicated a type of phimosis whose sole symptom was a foreskin that was arbitrarily determined to be too long.

Since the foreskin is the most highly innervated part of the penis, and since masturbation in genitally intact boys generally involves manually stimulating and manipulating the foreskin as well as manually sliding the mobile sheath of the penile skin over the shaft (a wide range of motion made possible by the double fold of the foreskin), masturbation was seen as a cause of reflex disease through the medium of the foreskin. In the absence of the Germ Theory of Disease, those American physicians who did not see masturbation alone as the primary cause of disease attributed bacterial, viral, and fungal diseases, as well as the pathological symptoms of malnutrition and overwork, to phimosis. Even in the absence of a diagnosis of phimosis, the foreskin itself was inculpated as a cause of disease. Phimosis in females, defined as an adherence of the clitoral prepuce to the clitoris, was viewed in the same light.

2.1.3. Pathologization of Sexual Function. In accordance with the Reflex Theory of Disease, erotic sensation was redefined as irritation, orgasm was redefined as convulsion, and erection of the penis was redefined as priapism. Physicians argued that these manifestations of sexual function were both symptoms and causes of disease, and, likewise, that stimulation of the genitals could cause disease in distant parts of the body such as the heart, brain, back, digestive organs, and eye.

The pathologization of normal male sexual function led first to the 'discovery' of spermatorrhea. Physicians defined spermatorrhea as a serious venereal disease whose sole symptom was the ejaculation of sperm under any condition other than connubial bliss. The release of sperm due to nocturnal emissions or masturbation was now classified as a venereal disease as dangerous as any other, if not more dangerous because more people suffered from it more often. Hundreds of case reports published in medical journals world-wide proved, to the satisfaction of most physicians, the harm of spermatorrhea. French physicians such as Claude-François Lallemand (1790-1853) and Léopold Deslandes (1797-1852) ${ }^{4}$ were the acknowledged world authorities on the treatment of spermatorrhea. They stuck long steel rods, also known as bougies, up the urethra, and, using silver nitrate, cauterized the urethra, prostate, and seminal vesicles in order to prevent the production and loss of sperm. In 1836, Lallemand also advised amputation of the foreskin in the most difficult cases of spermatorrhea as a way of preventing masturbation. $^{5}$

In the United States, Lallemand's use of circumcision caught the attention of Edward H. Dixon (1808-1880). In his 1845 book, A Treatise on Diseases of the Sexual Organs, Dixon revealed himself to be one of the first North American advocates of both therapeutic foreskin amputation and universal imposition of the ancient Hebrew rite of infant circumcision. ${ }^{6}$ Dixon claimed that phimosis, which he defined as an elongation of the foreskin, was the primary cause of most serious diseases. For a time, the American medical establishment ignored Dixon and Lallemand's advocacy of circumcision. Circumcision was forgotten for the next two decades while other surgical treatments for masturbation, phimosis, and spermatorrhea were developed. 


\subsection{Castration}

Since surgical amputation of body parts in general was considered thoroughly modern and advanced, physicians experimented with specific amputations of the sexual organs to treat masturbation. On June 22, 1842, the Boston Medical and Surgical Journal reported that Dr. Winslow Lewis of Boston had severed and tied the left spermatic artery of a young man being treated for "excessive masturbation." In 1843, however, one of the first reports of castration for masturbation was published by Dr. Josiah Crosby of Meredith Bridge, New Hampshire. ${ }^{8}$ After cathartics and emetics had failed to cure a 22 year-old youth whose health had reportedly been ruined by masturbation, Crosby castrated the boy and pronounced him cured. The American medical profession responded with interest. Two years later, in 1845, Dr. Samuel McMinn published in the pages of the Boston Medical and Surgical Journal a revolutionary case report of an insane woman living outside Tuscaloosa, Alabama, who had taken a razor and amputated "the whole of her external organs of generation." McMinn arrived at the scene and fully expected the woman to die from her massive wounds, but she survived. As her wounds healed, her reason miraculously returned. Fascinated by this development, McMinn speculated:

And the results of this case may suggest a remedy. Whether it was the great loss of blood, the removal of the external organs and the counter-irritation consequent, that cured the patient, is a question for the consideration of the profession. ${ }^{9}$

The title he gave to his report, however, betrayed his and, presumably, the journal editor's opinion on the source of the cure. The report was dramatically entitled "Insanity Cured by Excision of the External Organs of Generation."

Ten years later, in 1855, Dr. William T. Taylor published a similar report involving a cigar-maker from Philadelphia who had gone insane and then hacked off his penis and testicles with a broken bottle. ${ }^{10}$ Although he bled profusely, his wounds healed, and, miraculously, his reason was completely restored. No further proof was needed. A revolutionary new medical response to masturbatory insanity had been established just as the innovation of aseptic surgery was developing. Orthodox American medicine now embarked upon the wholesale amputation of the sexual organs as a cure for seemingly unrelated diseases. Insane asylums castrated inmates on a massive scale to prevent their masturbating and, ostensibly, to cure their insanity. Until the beginning of the Twentieth Century, boys who had been caught masturbating were frequently committed to insane asylums, circumcised, castrated, and shackled in their cells. ${ }^{11-12}$ Females were likewise subjected to "female castration," a surgery involving removal of the ovaries, with the intent of curing them of hysteria, epilepsy, or nymphomania.

\subsection{Spermectomy, Neurectomy, and Other Treatments}

Various other surgeries for masturbation were developed in order to destroy sexual desire. The operation of spermectomy was developed as a less drastic alternative to castration, and consisted of the surgical removal of the spermatic ducts rather than the testicles. ${ }^{13}$ Neurectomy also had a certain vogue in the 1890 s. In this operation, commonly performed on boys who had been caught masturbating, the physician severed the dorsal nerves of the penis in order to destroy penile sensation and function completely and permanently. ${ }^{1-15}$ American physicians also resorted to relatively less drastic measures such as slitting open the urethra, ${ }^{16}$ cauterizing the prostate,${ }^{17}$ inflicting corporal punishment, ${ }^{18}$ 
blistering the penis raw with caustic acids, ${ }^{19}$ flaying the penile skin with razor blades, ${ }^{20}$ sewing the prepuce shut with metal wire, ${ }^{21}$ encasing the genitals in plaster ${ }^{22}$ or in lockable metal cages, ${ }^{23}$ or fitting the penis with penile rings studded with sharp metallic teeth to discourage erections. ${ }^{24}$

For females, the preferred method of treatment for epilepsy and masturbation was clitoridectomy. One of the very first reports of therapeutic clitoridectomy was published in the San Francisco Medical Press in 1862. An abstract of the report read:

Dr. E. S. Cooper, Editor of the San Francisco Medical Press, relates two cases of removal by the scalpel of the clitoris in young girls who were inveterately addicted to the habit of masturbation, and for whom there was apparently no other alternative but hopeless insanity or an early grave. The result was a perfect cure in one case, and in the other the practice was broken up, and all the mental faculties improved except the memory, which is not restored. ${ }^{25}$

In the late 1860s, the British physician Isaac Baker Brown developed and promoted clitoridectomy as a cure for epilepsy. His claims of miracle cures through clitoridectomy led to the universal adoption of clitoridectomy in the English-speaking world as a cure for epilepsy, hysteria, and masturbation. In 1867, Dr. Baker Brown's conduct was called into question, and the London Obstetrical Society ordered him to cease performing the surgery. Although few doubted the proven value of clitoridectomy, Baker Brown was charged with failing to provide informed consent to his female patients. It was his method to chloroform and clitoridectomize all females who came into his clinic regardless of their ailment. The British medical press was unanimously in favor of banning Baker Brown from performing surgery, but he was vigorously defended in the American medical press. The editor of the New York-based journal, the Medical Record, strongly criticized the anti-clitoridectomy crusade in England, demanding to know, "What now will be the chance of recovery for the poor epileptic female with a clitoris?"26

\section{CIRCUMCISION AS THERAPY}

On December 1, 1855, English physician Jonathan Hutchinson (1828-1913) published his famous paper, "On the Influence of Circumcision in Preventing Syphilis."27 During the 1850s, London experienced a massive immigration of Jews from the ghettos of Eastern Europe. Hutchinson reported that, at the Metropolitan Free Hospital located in London's immigrant Jewish slum, fewer Jews than Englishmen sought treatment for syphilis. Being innocent of any understanding of the principles of statistical analysis, epidemiology, the Germ Theory of Disease, or the quarantine effect of the ghetto, Hutchinson speciously argued that only circumcision could account for the difference in disease rates. Hutchinson's paper was widely reprinted in foreign medical journals. Two years later, it was used as evidence in a religious tribunal. In 1857, a certain Dr. Levit, a Viennese Jew, under the influence of his Western education and, perhaps, the anti-circumcision movement within Reform Judaism, refused to allow his newborn son to be circumcised. The local Rabbinate, under the direction of Dr. Joseph Hirschfeld, held up Hutchinson's paper as evidence of the medical indications for circumcision and as sufficient justification for the Rabbinate to seize custody of Levit's son and forcibly circumcise the child. Levit was left without legal recourse to protect his own son. ${ }^{28}$

On the strength of Hutchinson's paper, the concept of circumcision as a therapeutic intervention now made a cautious reappearance in orthodox American medicine. At the 
August 12, 1861, meeting of the Boston Society for Medical Improvement, a Dr. White presented a paper in which he mentioned that circumcision could prevent masturbation. ${ }^{29}$ Seven years later, in 1868, Dr. Charles Bliss of Syracuse, New York, published an account of his successes in curing masturbation by partial amputation of the prepuce. ${ }^{30}$ In 1869 , a learned article appeared by the Baltimore physician, A. B. Arnold, describing the history of circumcision in the religious and tribal context of Jews, Muslims, and African animists. ${ }^{31}$ This new surgery was now legitimized by placing it in the context of a long history, albeit an Asiatic, non-Western history.

\subsection{The American Medical Association}

Hailed in his lifetime as the father of orthopedics and indeed as one of "the most distinguished benefactors whom the American medical profession has produced for the glory of medicine and the good of mankind," ${ }^{32}$ Dr. Lewis A. Sayre (1820-1900) was certainly among the most distinguished believers in the therapeutic powers of circumcision. Sayre served as vice-president of the American Medical Association in 1870 and eventually as president in 1880. At the 1870 meeting of the American Medical Association, Vice-President Sayre delivered a remarkable paper, "Partial Paralysis from Reflex Irritation, Caused by Congenital Phimosis and Adherent Prepuce." ${ }^{33}$ Supporting his claims with numerous case studies, and, using the most scientific methodology available at the time, Sayre proved to the satisfaction of his audience that a long, adherent foreskin was not only the cause of paralysis, but also hip-joint disease (tuberculosis of the hip joint), hernia, bad digestion, inflammation of the bladder, and clumsiness, In each case, Sayre reported that amputation of the foreskin had cured the disease. Throughout his career, Sayre urged physicians to examine the penis in all cases of childhood diseases. When phimosis, as defined by reflex theory, was found, Sayre advised immediate preputial amputation. Because of Sayre's professional reputation and impeccable credentials, major American medical schools readily adopted his theories of reflex disease and phimosis into their curricula.

During the late 1860 s and throughout the next decade, epilepsy increasingly became the focus of national attention, as indicated by the dramatic increase in the number of scientific publications on epilepsy. Capitalizing on the epilepsy hysteria, Sayre reported to the New York Pathological Society, in 1870, that phimosis was the cause of epilepsy. ${ }^{34} \mathrm{~A}$ few English physicians had been experimenting with circumcision to treat epilepsy since $1865,{ }^{35}$ but they connected the foreskin to masturbation and cited the prevention of masturbation as playing a role in the cure of epilepsy. Sayre maintained that a long foreskin, all by itself, had the power to induce violent epileptic convulsions, and that circumcision had cured every case of epilepsy. As with paralysis, hundreds of case reports were published over the next 75 years, validating Sayre's advocacy of circumcision to cure epilepsy.

At the 1875 meeting of the American Medical Association, Sayre delivered another important lecture on phimosis. He informed his audience that he had discovered that a long, adherent foreskin could cut off circulation to the spinal column and thereby cause lameness, curvature of the spine, paralysis of the bladder, and club-feet. ${ }^{36}$ Miraculously, he reported, circumcision brought immediate cure to all patients, including the patient with club-feet. In the same lecture, he also presented several cases in which clitoridectomy brought instantaneous cure to paralytic girls. 


\subsection{The Masturbation Hysteria and Circumcision}

The masturbation hysteria continued unabated throughout the last decades of the Nineteenth Century. From 1800 to the early 1870 s, there was an astounding $750 \%$ increase in the number of medical journal articles on masturbation. From the 1870 s to the $1880 \mathrm{~s}$, the number of articles on masturbation increased by $25 \%$ and, from the 1880 s until 1900 , the rate of increase was augmented to $30 \%$. Among the more influential physicians who noticed this dramatic increased focus on masturbation and contributed to it were Abraham Jacobi and M. J. Moses. Jacobi (1830-1919) was the President and founder of the American Pediatric Society, the first Chairman of the Section on Diseases of Children of the American Medical Association, President of the New York State Medical Society, President of the New York Academy of Medicine, and President of the Association of American Physicians. Both Jacobi and Moses claimed that Jews were immune to masturbation solely because they were circumcised, and that non-Jews were especially prone to masturbation and to the horrible diseases that resulted from masturbation solely because they had a foreskin. Moses' and Jacobi's authoritative studies, alleging that the foreskin caused epilepsy, paralysis, malnutrition, hysteria, and other nervous disorders, were cited by medical writers for the next few decades. ${ }^{37}$

In 1871, Moses published an exceedingly influential, and widely-cited article, "The Value of Circumcision as a Hygienic and Therapeutic Measure," in the New York Medical Journal. Moses stated, in part:

As an Israelite, I desire to ventilate the subject, and, as a physician, have chosen the medium of a medical journal, that I may not be trammelled in my expressions, as I necessarily would be were I confined to the pages of an ordinary paper....I refer to masturbation as one of the effects of a long prepuce; not that this vice is entirely absent in those who have undergone circumcision, though I never saw an instance in a Jewish child of very tender years, except as the result of association with children whose covered glans have naturally impelled them to the habit. ${ }^{38}$

It is quite clear from the context that the title word "Hygienic" has a different meaning than it does today. At that time, circumcisers used words such as hygiene to denote moral hygiene, not personal hygiene. Moses' paper made a big impact on American physicians who now argued that castration should be abandoned in favor of circumcision since circumcision cured all the same diseases as castration but did not affect procreation, as demonstrated by the example of the Jews. An article that appeared in the Medical Record in 1895 explained the anti-masturbation theory of circumcision thus:

In all cases [of masturbation],...circumcision is undoubtedly the physicians' closest friend and ally.... To obtain the best results one must cut away enough skin and mucous membrane to rather put it on the stretch when erections come later. There must be no play in the skin after the wound has thoroughly healed, but it must fit tightly over the penis, for should there be any play the patient will be found to readily resume his practice, not begrudging the time and extra energy required to produce the orgasm. It is true, however, that the longer it takes to have an orgasm, the less frequently it will be attempted, consequently the greater the benefit gained. ${ }^{39}$

\subsection{More Miracle Cures}

The list of previously incurable diseases that orthodox physicians now claimed to have cured through circumcision continued to grow. An 1895 textbook declared: 
Only within recent years, since the physiology of nervous reflexes has become better understood, has [circumcision] become a generally accepted operation with thinking surgeons. Not alone for local conditions is the operation demanded. In all cases in which male children are suffering nerve tension, confirmed derangement of the digestive organs, restlessness, irritability, and other disturbances of the nervous system, even to chorea, convulsions, and paralysis, or where through nerve waste the nutritive facilities of the general system are below par and structural diseases are occurring it should be considered as among the lines of treatment to be pursued. $^{40}$

Thousands of such reports were published in reputable American medical journals. In 1890, Dr. William D. Gentry (1836-1922) published a typical report, "Nervous Derangements Produced by Sexual Irregularities in Boys," which detailed the frightening and varied consequences of phimosis as well as the miracle cure to be found in circumcision.

Whilst I was physician to the Children's home at Kansas City, in 1884-5, there was brought to the Home from some similar institution in Chicago, a child two years and a half old, who was blind, deaf and dumb. It was nervous, fretful, and caused the matron a great deal of trouble. It was dwarfed and presented the peculiar general appearance which nearly every boy will present who is afflicted with sexual derangement. As soon as I saw the child the thought came into my mind that his trouble had some connection with such derangement, and on making an examination found that he had phimosis. With the consent of the father of the boy, I operated, and removed the derangement. In two months the child could see and make sounds as if trying to speak. In six months he could hear, see and speak. ${ }^{41}$

\subsection{Anti-Sexual Nature of Circumcision}

The early promoters of circumcision fully acknowledged the sexual functions of the foreskin and advocated circumcision as an intentional destruction of those functions. One of many such acknowledgments was published in the November 3, 1900, issue of Medical News:

Finally, circumcision probably tends to increase the power of sexual control. The only physiological advantage which the prepuce can be supposed to confer is that of maintaining the penis in a condition susceptible to more acute sensation than would otherwise exist. It may increase the pleasure of coition and the impulse to it: but these are advantages which in the present state of society can well be spared. If in their loss increase in sexual control should result, one should be thankful. ${ }^{42}$

In 1902, an editorial in Medical News, made clear the anti-sexual motivation behind the doctrine of circumcision as a hygienic measure.

Another advantage of circumcision...is the lessened liability to masturbation. A long foreskin is irritating per se, as it necessitates more manipulation of the parts in bathing.... This leads the child to handle the parts, and as a rule, pleasurable sensations are elicited from the extremely sensitive mucous membrane, with resultant manipulation and masturbation. The exposure of the glans penis following circumcision...lessens the sensitiveness of the organ....It therefore lies with the physicians, the family adviser in affairs hygienic and medical, to urge its acceptance. ${ }^{43}$ 


\section{EARLY TWENTIETH CENTURY}

After the Germ Theory of Disease had become widely accepted and vitamins had been identified, most microbial diseases, such as tuberculosis, were silently removed from the list of diseases caused by phimosis. Still, the majority of American physicians tenaciously clung to the belief that phimosis was the cause of diseases, such as epilepsy, that were not yet properly understood. Year by year, the list of diseases caused by phimosis continued to grow. Physicians even attributed death to phimosis. ${ }^{44}$

\subsection{Abraham L. Wolbarst and the Cancer Scare}

In the January 19, 1914, issue of the Journal of the American Medical Association, Dr. Abraham L. Wolbarst (1872-1952), a urologist practicing, among other places, at Beth Israel Hospital and the Jewish Memorial Hospital in New York, published the first of a series of papers indicting the foreskin as a cause of disease. This marked the start of a nearly forty-year crusade for mass involuntary circumcision. Wolbarst was a prominent and influential member of both the American Medical Association and the notorious American Society of Sanitary and Moral Prophylaxis, a reform organization committed to the abolition of extra-marital and childhood sexuality. His views on sexuality were characteristically extreme. For example, in the 1930s, Wolbarst argued that adult masturbators should be sterilized and forbidden to marry. ${ }^{45}$ In his 1914 paper, "Universal Circumcision as a Sanitary Measure," Wolbarst stated:

[I]t is generally accepted that irritation derived from a tight prepuce may be followed by nervous phenomena, among these being convulsions and outbreaks resembling epilepsy. It is therefore not at all improbable that in many infants who die in convulsions, the real cause of death is a long or tight prepuce. ${ }^{46}$

Wolbarst also added that:

It is the moral duty of every physician to encourage circumcision in the young.... ${ }^{47}$

From the context of his paper, it is clear that the title word "Sanitary" denotes morality rather than the absence of germs or dirt. It is important to note that, until this time, circumcision was primarily used as therapy for children and adults, but not as prophylaxis for infants. As a result of Wolbarst's ceaseless lobbying, the radical notion of universal, non-therapeutic, involuntary neonatal circumcision slowly gained acceptance among American physicians. Medical textbooks were rewritten to instruct obstetricians and pediatricians to examine the penis of every newborn boy to determine if the foreskin was retractable. If not, it was advised that it be immediately amputated.

By the mid-1930s, when most physicians had converted to the theory that epilepsy was a problem of the brain, Wolbarst continued to insist that epilepsy and convulsions were caused by a tight foreskin. ${ }^{48}$ While never abandoning this theory, Wolbarst must have sensed the need to reformulate his arguments to appeal to the changing interests of the public. In the early decades of the Twentieth Century, the number of popular magazine articles on epilepsy had steadily dwindled. The number of articles on cancer, however, had risen dramatically, reflecting a shift in national focus. The Reader's Guide to Periodical Literature listed thirteen articles in popular magazines under the "cancer" entry between 1900 and 1904. By 1909, the number had doubled, and by 1928, the number of 
popular articles on cancer had increased by $569 \%$ since 1900 . At a peak in this surge of national concern over cancer, Wolbarst published the definitive paper on circumcision as preventive of penile cancer in 1932. Based on his contention that Jews were immune to penile cancer, Wolbarst theorized that penile cancer was caused by "the accumulation of pathogenic products in the preputial cavity." ${ }^{49}$ No scientific validation was offered in support of this idea, yet based on this paper, the theory that smegma was a carcinogen became widely accepted as fact in the United States.

\subsection{Advances in Foreskin Anatomy and Development}

In 1932, a research team at the University of Pennsylvania, led by Dr. H. C. Bazett, published a detailed anatomical description of the innervation of the foreskin. They noted that the foreskin was richly innervated and capable of detecting very fine distinctions of touch and temperature. ${ }^{50}$ In the following year, Dr. Glenn A. Deibert, of the Daniel Baugh Institute of Anatomy at Jefferson Medical College, made a careful investigation of the development of the foreskin in utero and the process of separation of the foreskin from the glans after birth. ${ }^{51}$ Deibert demonstrated that the adherence of the foreskin to the glans was not phimosis or a birth defect, but a normal stage of penile development. In 1935, the British anatomist, Richard H. Hunter, of the Department of Anatomy at Queen's University in Belfast, similarly published a detailed description of the embryological development of the foreskin. Perhaps because their findings did not support the current view of the foreskin as a useless, pathogenic defect, all three studies were ignored by the American medical establishment. ${ }^{52}$

\subsection{Invention of the Gomco Clamp}

The profit margin for circumcision rose with the mass-manufacture and widespread distribution of the now ubiquitous Gomco Clamp, first invented in 1934 by Aaron Goldstein and Dr. Hiram S. Yellen. Gomco is an acronym for the GOldstein Manufacturing COmpany, which later changed its name to the Gomco Surgical Manufacturing Corporation of Buffalo, New York. This steel device is still widely used today to crush the male baby's foreskin prior to its amputation. The standardization of surgical technique made possible the more rapid institutionalization of circumcision.

\subsection{Popular Perceptions}

The September 1941 issue of Parents' Magazine contained the first article on routine circumcision that had ever appeared in a popular magazine of such wide distribution. The author, Dr. Alan F. Guttmacher, an obstetrician at Johns Hopkins University Medical School, presented the public with many of the same myths and scare tactics that had been in use since the Nineteenth Century. For instance, Guttmacher admitted that "circumcision causes blunting of male-sexual sensitivity," ${ }^{, 3}$ but argued that this was an advantage. In addition to mentioning Wolbarst's relatively new myth regarding penile cancer, Guttmacher presented the public with a myth of his own invention, one that had never appeared in the medical literature, and one that directly contradicted the scientific findings of Deibert and Hunter. With the authority of his professional title and institutional affiliations, he stated to the American people, as fact, that: 
Present-day hygiene requires that the prepuce, the hoodlike fold of skin which covers the end of the penis (glans) be drawn back daily and the uncovered glans thoroughly washed. Trouble occurs if this is neglected, for the secretion from the multiple glands lining the inside of the hood becomes caked, and within a few days the material may set up an inflammation. Such inflammation may lead to the growth of slender, strandlike bands of tissue between the inside of the prepuce and the glans, gluing the two together, thus forming an adherent foreskin. ${ }^{54}$

To avert this frightening scenario, Guttmacher advised the public to let their children be circumcised at birth because it "makes care of the infant's genitals easier for the mother," and because it "does not necessitate handling of the penis by the infant's mother, or the child himself in later years, and therefore does not focus the male's attention on his own genitals. Masturbation is considered less likely." 55 Guttmacher's article sought to validate the perceived associations between the foreskin, difficult hygiene, inevitable masturbation, genital defects, and taboo handling of the boy's penis. It also served to legitimize, for the benefit of the public, the increasingly common practice of large urban hospitals instituting programs of involuntary circumcision of the newborn.

\subsection{Abraham Ravich and Cancer of the Prostate and Cervix}

In 1942, expanding upon Wolbarst's theory of smegma as a carcinogen, and repeating the myth of Jewish immunity to disease, Abraham Ravich (1889-1984), a urologist at Israel Zion Hospital in Brooklyn and one of the Twentieth Century's most active crusaders for mass involuntary circumcision, postulated a causal link between the foreskin and prostate cancer. He also restated the obscure theory (proposed without scientific documentation in $1926^{56}$ ) that cervical cancer of the female was caused by male smegma. ${ }^{57}$ The popular news magazine, Newsweek, reported Ravich's claim and quoted his demand that there "be an even more universal practice of circumcising male infants." Amended to the long list of achievements he prepared for his entry in Who's Who in America, Ravich proudly credited himself with being the first to report on circumcision of newborn males to prevent genital cancers. ${ }^{59}$

\section{WORLD WAR II}

During World War II, certain military medical doctors instituted a campaign of mass circumcision of soldiers in all branches of the armed forces. Even at the height of the war, Navy physician Lieutenant Marvin L. Gerber confidently stated in the pages of the United States Naval Medical Bulletin that circumcision was one of the most commonly performed surgical operations in the Navy, even more commonly performed than trauma surgery. ${ }^{60}$ Military medical records alleged that an epidemic of phimosis and paraphimosis among soldiers had justified the mass circumcision campaign. Soldiers were subjected to unannounced inspections of their penises, called "short arm inspections." Soldiers with intact penises were declared "phimotic" and sent off to be circumcised, sometimes under threat of court martial.

\subsection{Sexually Transmitted Diseases and the Scapegoating of Blacks}

Military documents reveal that Blacks were blamed for spreading venereal disease in the military and were thus especially targeted for involuntary circumcision. Military physicians such as Eugene A. Hand (1909- circa 1972), a dermatologist who practiced 
during the war at the Naval Hospital at St. Albans, New York, were responsible for the military adopting this view of Blacks as dangerous disease carriers. Another physician, Captain Leonard L. Heimoff, an officer in the Medical Corps of the United States Army, declared that "Negro troops were causing 70 percent of all new cases of venereal disease." Heimoff organized covert military units to monitor the sexual activities of civilian Black communities. ${ }^{61}$ Heimoff's report, like that of Hand and others, concluded that Blacks could not be taught to practice personal hygiene and that they could not be trusted to avoid contracting venereal diseases.

The war coincided with an increased national focus on venereal disease. From 1930 to 1940 , there was a dramatic $192 \%$ increase in the number of popular magazine articles on venereal disease. Following a surge between the years 1941 and 1943, the number of popular articles on venereal disease increased at a rate of $17 \%$ from 1940 to 1947 , but dropped precipitously thereafter. At the height of the popular hysteria over venereal disease, Hand delivered a paper, entitled "Circumcision and Venereal Disease," at the annual meeting of the American Medical Association, held in Atlantic City on June 12, 1947. Comparing the rates of venereal disease between Jews, Gentiles and Blacks, Hand theorized that circumcision could prevent venereal disease. He wrote:

\footnotetext{
Circumcision is not common among Negroes....Many Negroes are promiscuous. In Negroes there is little circumcision, little knowledge or fear of venereal disease and promiscuity in almost a hornet's nest of infection. Thus the venereal rate in Negroes has remained high. Between these two extremes there is the gentile, with a venereal disease rate higher than that of Jews but much lower than that of Negroes. ${ }^{62}$
}

In the same study, he also found that cancer of the tongue was more common among those with foreskins than among Jews. Newsweek reported Hand's sensational findings in detail, thereby increasing the popular perception that a policy of mass involuntary circumcision was both scientifically based and of critical importance for the security of the nation. $^{63}$

\subsection{Fate of the Foreskin}

In December 1949, the British Medical Journal published the landmark study, "The Fate of the Foreskin," by a bright young Cambridge physician, Douglas M. T. Gairdner (1910-1992).$^{64}$ Drawing on the embryological and histological research of Deibert and Hunter, and presenting his own meticulous research on preputial adhesion and retractability in children, Gairdner successfully debunked the phimosis myth. Demonstrating that non-retractability, adherence, and length were normal conditions of the juvenile foreskin, Gairdner also confidently debunked all the alleged benefits of circumcision. His paper generated enormous interest among physicians and attracted the interest of the British government. On the basis of Gairdner's findings, the new British National Health Service elected not to pay for neonatal circumcision, causing the rate of neonatal circumcision in Britain to plummet.

\section{CORPORATE INSTITUTIONALIZATION OF CIRCUMCISION IN THE COLD WAR ERA}

In the United States, however, Gairdner's paper was largely ignored, and the phimosis hysteria continued unabated. Medical textbooks continued to advise obstetricians to 
examine every newborn boy for a foreskin that was either too long or adherent, and to perform an immediate foreskin amputation if these symptoms of "phimosis" were detected, as they almost always were. In 1953, two obstetricians, Richard L. Miller and Donald C. Snyder, published an influential paper in the American Journal of Obstetrics and Gynecology, calling for the immediate circumcision of all newborn males after birth. ${ }^{65}$ Ignoring Gairdner and relying heavily upon the writings of Wolbarst, Miller and Snyder argued that 'phimosis' required immediate surgical correction, and that "circumcision will reduce the incidence of onanism [masturbation]," "increase the male libido," and "increase longevity and immunity to nearly all physical and mental illness." They also argued that immediate circumcision following birth was convenient for the doctor and economically in the best interest of the hospital. The leading obstetrical textbooks were rewritten to include Miller and Snyder's arguments. ${ }^{66}$

\subsection{New Cancer Scare}

The 1950's saw a dramatic increase in the national focus on cancer. While the focus on cancer had abated considerably during the war, the number of articles on cancer appearing in popular magazines increased 182\% from 1943 to 1951 . From 1951 to 1955, the number of articles increased by $32 \%$, and from 1955 to 1957 , the rate increased by another $72 \%$. In timing with this renewed and dramatically increased popular focus, Ravich published another paper in 1951, "Prophylaxis of Cancer of the Prostate, Penis, and Cervix by Circumcision," alleging that 25 thousand cancer deaths each year were caused by the foreskin and that 3 to 8 million American men then living had contracted prostate cancer as a result of having a foreskin. Ravich concluded that a program of mass involuntary circumcision was necessary as an "important public health measure." ${ }^{\circ 7}$ Dr. Ernest L. Wynder of Manhattan's Memorial Center for Cancer and Allied Diseases took up Ravich's theory of cervical cancer. In 1954, he published a lengthy paper that purported to show that universal male neonatal circumcision could prevent cervical cancer in women. ${ }^{68}$ The popular news magazine, Time, published a detailed article of Wynder's study, thereby reinforcing popular support and acquiescence to the activities of the burgeoning circumcision industry. ${ }^{69}$

Meanwhile, there were repeated calls for routine female circumcision at birth. In the 1950s, American physicians stepped up their efforts to make adult female circumcision more widely practiced. In 1959, Dr. W. G. Rathmann of Ingelwood, California, published an important article promoting wide-scale female circumcision as a cure for psychosomatic illness and marital problems. He also took the occasion to tout his newly patented female circumcision clamp. ${ }^{70}$

\subsection{Kaiser, Gomco, and Europe}

Increasing numbers of corporation-run American hospitals and private insurance companies in large urban centers entered into the profitable routine neonatal circumcision business. Private hospitals instituted policies of immediate and automatic circumcision of all male neonates in the delivery room. For instance, in 1950, at Kaiser Foundation Hospital in Oakland, California (flagship of Kaiser Foundation, one of the oldest and largest health management organizations in the United States), out of 889 live male births, 812 $(92.1 \%)$ were circumcised immediately after birth. ${ }^{71}$ Likewise, many urban hospitals adopted policies of circumcising all genitally intact boys during other operative procedures such as tonsillectomy. 
In the late 1950s, the American circumcision industry began efforts to spread circumcision to Europe. Of all European countries, East and West Germany were most often targeted for circumcision propaganda from the United States. Around 1957, the Gomco Surgical Manufacturing Corporation established a European distribution network headquartered in the West German city of Ulm. ${ }^{72}$ In the same year, Kaiser Foundation Hospital representatives worked with Otto Dietz, a minor communist official in the East Berlin Secret Police, to promote the mass circumcision of German babies. ${ }^{73}$ In 1959,150 German babies born in a state-run clinic in the West German city of Darmstadt were experimentally circumcised without anesthesia as a promotion for the Gomco Clamp. ${ }^{74}$ In 1963, Dr. H. Koester arranged for the maternity clinic at the University of Gießen to adopt a policy of mass circumcision by Gomco clamp of all German boys born there. ${ }^{75}$ By 1968 , arrangements were made for 2,832 East German babies to be circumcised as a promotion for the Gomco clamp. ${ }^{76}$

In the early 1970s, however, circumcision met with increasing disfavor among medical officials in both East and West Germany, and the circumcision experiments came to an end. Meanwhile, Gomco promoters had moved into Denmark and arranged for 18 Danish newborns to be circumcised in $1973 .^{77}$ Along with publicity photographs of the Gomco clamp, the results were published in glowing terms in the Danish medical press. The Danish people, however, strenuously resisted the idea of allowing their children's sexual organs to be surgically altered for any reason, and the circumcision campaign faded.

\subsection{Professional Opposition to Mass Circumcision}

American opposition to involuntary circumcision did exist. In 1956 and 1959, respectively, Dr. Richard K. Winkelmann, a Fellow in Dermatology at the Mayo Clinic in Rochester, Minnesota, published two anatomical studies documenting the intense erogenous innervation of the foreskin and identifying the foreskin as a specific erogenous zone. $^{78-79}$ In an era that was growing increasingly hostile to sexuality, however, Winkelmann's studies were ignored. In 1954, Ravich's theory that the foreskin caused prostate cancer was disproven, ${ }^{80}$ and as early as 1962 , the myth that the male foreskin caused cervical cancer in women was also scientifically disproven. ${ }^{81}$ In 1963, another scientific study disproved Wolbarst's theory that penile smegma was a carcinogen. ${ }^{82}$ In 1965 , the Journal of the American Medical Association published a revolutionary article by Dr. William Keith C. Morgan, "The Rape of the Phallus." ${ }^{83}$ Morgan's paper carefully debunked all the then-current arguments hospitals used to justify involuntary circumcision and thereby generated enormous controversy in the American medical community.

The year 1968 saw the publication of yet another ground-breaking study on the nature of the juvenile foreskin. The respected British pediatric journal, Archives of Disease in Childhood, published the exhaustive research of Danish pediatrician Jakob Øster, who had examined the incidence of preputial adhesion in 9,545 Danish schoolboys aged 6-17 years. ${ }^{84}$ Like Gairdner nineteen years earlier, Øster debunked the phimosis myth and demonstrated that balanopreputial adhesion was not a birth defect but a normal stage of penile development. Øster further demonstrated that preputial separation was a normal biological process that, in many cases, required at least a decade to complete. His research revealed that no intervention was indicated and, more importantly, that inappropriate attempts to hasten development of the preputial space could damage the immature foreskin. Øster's study was widely read by European physicians and it significantly advanced the scientific understanding of the penis. In America, Øster seems to have been ignored. In 1970, the 
Journal of the American Medical Association published an important study, "Whither the Foreskin?," by Dr. E. Noel Preston, which thoroughly debunked all the circumcision myths. ${ }^{85}$ Preston's review of the literature influenced the American Academy of Pediatrics (AAP) Committee on Fetus and Newborn in 1971 to publish the 5th edition of its Standards and Recommendations for Hospital Care of Newborn Infants with the following statement on circumcision:

There are no valid medical indications for circumcision in the neonatal period. ${ }^{86}$

In the late 1970s, as Americans were growing increasingly aware of the abuses of power rampant throughout the nation's social institutions, influential grass-roots movements protesting the forced circumcision of American children sprang up nationwide. In the face of ridicule and pressure from health-care professionals, many American parents actively refused to permit their newborn sons to be circumcised. At the same time, the sweeping reforms gained by the informed-consent movement now required doctors to explain the probable outcome of any surgery, state the known risks, offer alternative treatments, and obtain written consent from the patient. Circumcision, too, now required a consent form, but since the person being operated on was developmentally incompetent to give consent, spokesmen for the circumcision industry claimed that parents could give consent by proxy. By deceptively presenting involuntary circumcision of the newborn as the "parents' choice," circumcision advocates hoped to obfuscate the crucial fact that the person who faced the risks and permanent consequences of surgical alteration of his sexual organs was still not allowed a choice. Critics countered that doctors had no legal power to concede control of the baby's genitals to the parents because doctors had no de jure legal power over the genitals of babies in the first place.

\subsection{Backlash from the Circumcision Industry}

The 1970s saw the high-water mark of involuntary circumcision in the United States. With and without parental consent, some hospitals raised the rate of neonatal circumcision to over $90 \%$ during the late 1970 s and early 1980s. Circumcision advocates from large urban areas accepted positions in small rural hospitals in America's heartland and instituted programs of mass involuntary circumcision of the newborn in parts of the country where routine circumcision was previously unknown.

As part of this backlash, babycare books, popular medical magazines, and popular health books circulated myths to the effect that a boy not circumcised in infancy would be psychologically damaged if he ever realized that his father's circumcised penis differed from his own. ${ }^{87-89}$ Another myth that was especially effective in controlling middle-class parents played upon their anxieties concerning conformity and social status by alleging that an intact boy would be made to feel inferior to his circumcised classmates in a highschool locker room. ${ }^{90}$

Anatomical and physiological information on the foreskin was omitted from American anatomy textbooks and replaced with pro-circumcision arguments. ${ }^{91-92}$ Even anatomical representations of the penis in standard urology textbooks silently omitted the foreskin and presented the penis as being circumcised, as if it were so by nature. ${ }^{93}$ Those few anatomical drawings of the natural human penis that could be found generally represented the anatomy of the foreskin incorrectly. The natural human penis became unfamiliar to the new generation of Americans - physicians and laymen alike - many of whom had never seen one. As an example of the type of information disseminated to American medical stu- 
dents in the 1970s, the third edition of Campbell's Urology, the standard and most respected American urological textbook, declared:

Phimotic stenosis causes extreme difficulty of urination with straining and crying; hernia or rectal prolapse may be secondary end results. Urinary infection is a frequent complication, and is often directly predisposed to by the preputial obstruction. Malnutrition, epistaxis, convulsions, night terrors, chorea, and epilepsy have all been reflexly attributed to phimosis. ${ }^{94}$

The same textbook also declared:

Parents readily recognize the importance of local cleanliness and genital hygiene in their children and are usually ready to adopt measures which may avert masturbation. Circumcision is usually advised on these grounds. ${ }^{95}$

The masturbation hysteria, though well over 100-years-old, was obviously not over. In October 1972, the American Academy of Pediatrics Section of Urology appointed a committee to meet with a committee from the Fetus and Newborn Section and a representative from general pediatrics to discuss the question of circumcision in the newborn in order to provide guidance to health insurance carriers who had been asking the AAP whether routine neonatal circumcision should be covered in their insurance programs. The results were never officially published as such, but were unofficially presented by Dr. Thomas H. Guthrie, the chairman of the committee, in a paper delivered to the Urology Section of the American Medical Association Convention in New York City in June of 1973, and later published in Pediatrics. ${ }^{96}$ Guthrie argued for the adoption of more widespread routine neonatal circumcision and continuation of insurance coverage.

Female circumcision had not entirely disappeared from American medical practice and, in 1973, Dr. Leo Wollman, a gynecological surgeon at Maimonides Hospital in Brooklyn, published an article advocating female circumcision as a cure for frigidity. ${ }^{97}$ Wollman's appeal was geared to the ethos of the sexual revolution of the 1970s. Surgical reduction of male and female genitalia, it was argued, would improve and increase the pleasure of orgasm. This was the exact opposite of the message given a hundred years earlier, and the sudden reversal of strategy convinced critics that American circumcisionists were willing to say anything to push genital amputation on a gullible but increasingly rebellious public. The search for new excuses to justify routine circumcision is revealing.

To make matters worse for the advocates of circumcision, a newly formed American Academy of Pediatrics ad hoc Task Force Committee on Circumcision issued an even stronger policy statement on circumcision in 1975. The statement concluded:

There is no absolute medical indication for routine circumcision of the newborn....A program of education leading to continuing good personal hygiene would offer all the advantages of routine circumcision without the attendant surgical risk. Therefore, circumcision of the male neonate cannot be considered an essential component of adequate total health care. ${ }^{98}$

\subsection{Legal Action for Children's Rights}

In the early 1980 s, the medical press reported that several lawsuits had been filed in California against doctors and hospitals, charging that they had violated the constitutional rights of the plaintiffs by circumcising them without their permission soon after birth. ${ }^{99-100}$ These cases were filed in order to establish in a court of law that parents have no right to consent to a medically unnecessary surgery on their child based on the 1975 AAP policy 
statement that circumcision was medically unnecessary. The acknowledged lack of medical justification for circumcision put circumcisers at risk for litigation, but more importantly, the Constitutional challenge to the practice of subjecting children to involuntary circumcision threatened to dismantle the lucrative circumcision industry, which, in 1986, was estimated to generate more than $\$ 200$ million annually. ${ }^{101}$ If the practice of involuntary circumcision of the newborn were to survive, a new medical excuse would have to be found.

\subsection{The Urinary Tract Infection Scare}

In the mid-1980s, urinary tract infections (UTI) emerged as that new excuse. While no articles on this rare disorder had yet appeared in popular magazines, the medical literature reflected a surge of scientific interest in UTI. For the period from 1966 to 1974 , a MEDLINE database keyword search uncovered only 4 published studies on UTI, yet from 1975-1979, 65 studies were published. From 1980 to 1984 , the number had nearly tripled, and from 1985 to 1989,350 studies were published. While the national rate of UTI had not changed from 1966 to 1989 , the astounding $8,650 \%$ increase in the number of published studies reflected a definite surge in scientific interest. As part of this increased interest, Dr. Charles M. Ginsburg and Dr. George H. McCracken, Jr. of Dallas, Texas, in 1982, quietly published a study of 100 infants with acute UTI. Because only 3 of the 62 male infants were circumcised, the authors briefly speculated that non-circumcised males might have an increased susceptibility to UTI, but admitted that "perineal hygiene was inadequate in many patients." 102 In 1985 , evidently intrigued by the possibilities of this speculation, Dr. Thomas E. Wiswell (1951-), then a neonatologist at Brooke Army Medical Center in Texas, sought to verify it by publishing in Pediatrics the first of many studies promoting the theory that circumcision might reduce the rate of UTI. ${ }^{103}$ Wiswell's first nonrandomized, retrospective review of hospital charts suggested a UTI rate of $1.4 \%$ for intact boys and $0.14 \%$ for circumcised boys. Although the difference in rates was only 1.2 percentage points, it was made to appear significant by being stated in terms of a $10 \%$ increase. Proponents greeted the publication of Wiswell's study as the long-awaited indication for the practice.

Significantly, one of the published letters to the editor of Pediatrics regarding Wiswell's study directly addressed the California lawsuits. The author, Dr. Aaron J. Fink (1926-1994), a urologist from Mountain View, California, like Wolbarst and Ravich before him, actively lobbied for mass involuntary circumcision. Fink's publications reveal that he was among those most disturbed by the prospect of legal action against circumcisers. In his letter, Fink ridiculed the contention that circumcision required the consent of the patient. ${ }^{104}$ In his published reply, Wiswell assented that the alleged medical indication he had discovered obviated any requirement to obtain patient consent before operating. ${ }^{105}$ McCracken, however, later stated that "because the long-term outcome of UTI in uncircumcised male infants is unknown, it is inappropriate at this time to recommend circumcision as a routine medically indicated procedure." 106

Nevertheless, popular medical books and babycare books were updated to include the UTI myth..$^{107-109}$ National news magazines, such as Newsweek ${ }^{110}$ and U.S. News and World Report, ${ }^{11}$ ran feature stories on Wiswell and the new UTI excuse for subjecting infants to involuntary circumcision. Most males have never experienced a UTI, and the UTI myth had little power to influence fathers, but sociological research had shown that it was mothers, far more than fathers, who signed the circumcision consent form. ${ }^{112-114}$ Unpleasant and painful bouts of UTI are significantly more common among females, ${ }^{115-116}$ and the 
new UTI scare tactic proved to be especially efficient in frightening young mothers into agreeing to the circumcision of their sons. Unlike the unsubstantiated or disproven excuses for neonatal circumcision, such as the prevention of geriatric genital cancers and sexually transmitted diseases, UTI could afflict infants. Wiswell alleged that the foreskin posed a serious threat to the individual's life in the first few weeks after birth and its presence could increase the risks of the potential complications of UTI, such as kidney failure, meningitis, or death. ${ }^{117-118}$

An article in the September 1986 issue of Pediatric News uncovered the fact that Wiswell and Dr. Terry D. Allen were petitioning the AAP to form another ad hoc Task Force Committee on Circumcision in order that it might issue a policy statement supporting routine circumcision. Reacting to the trend of insurance companies ceasing payment for neonatal circumcision on the basis of the 1975 AAP policy statement on circumcision, Wiswell warned, "If 10 years from now there are uncircumcised children on dialysis with kidney damage associated with UTI, insurers who wouldn't pay for circumcision might be held liable." 119 Oddly, Wiswell presented himself to reporters as an opponent of routine circumcision, saying, "I tell them [parents] that I personally don't like the procedure and don't recommend it, but if they want if performed, I will do it." Under the leadership of Dr. George W. Kaplan, the chairman of the AAP Urology Section, the AAP resisted this pressure for three years.

In 1989, a new AAP Task Force Committee on Circumcision was formed and chaired by Dr. Edgar J. Schoen (1925- ), a pediatrician practicing at Kaiser Foundation Hospital in Oakland since 1954. After intense debate, the Task Force was able to issue a new statement that took into account Wiswell's UTI hypothesis. The statement tenuously concluded:

\footnotetext{
Newborn circumcision has potential medical benefits and advantages as well as disadvantages and risks. When circumcision is being considered, the benefits and risks should be explained to the parents and informed consent obtained. ${ }^{120}$
}

By closing the legal loophole created by the 1975 statement, the 1989 statement effectively protected circumcisers from any further lawsuits while avoiding making any overtly unscientific claims. Sensitive to the embarrassing fact that European countries had traditionally rejected American attempts to export involuntary or even voluntary circumcision, Schoen, from his office at the renamed Kaiser Permanente Medical Center in Oakland, tried in 1991 to persuade Northern European countries to adopt programs of routine infant circumcision. ${ }^{121}$ The terse reply to Schoen's overtures, written by two of Sweden's most eminent physicians and published in a leading Swedish medical journal, invoked the critical issues of fairness, human rights, and medical ethics. Indicating that it was a violation of human rights to be subjected to such a procedure, the authors asserted that it was only fair to postpone a decision until the young male could make a choice of his own. Moreover, the authors patiently explained, since an Ethics Committee on Experimental Animals would never accept a procedure such as unanesthetized circumcision on laboratory animals, Europe could hardly justify subjecting its own children to such a procedure. $^{122}$

\subsection{The HIV Scare}

In the early 1980s, the emergence of the human immunodeficiency virus (HIV) and acquired immune deficiency syndrome (AIDS) attracted the attention of both the Ameri- 
can people and the medical establishment. As an indicator of this surge in national focus on AIDS, the number of popular magazine articles on AIDS rose from 9 in 1982 to 68 in 1983. From 1983 to 1987 , the number of popular articles increased by $657 \%$. Capitalizing on this surge in national focus, Dr. Aaron J. Fink published his newly-invented theory that circumcision could prevent AIDS. In an unexpected departure from its fastidiously high scientific standards, the New England Journal of Medicine actually published Fink's theory in 1986, without demanding any scientific substantiation. ${ }^{123}$

During 1987 and 1988, Fink tirelessly lobbied the California Medical Association (CMA) to adopt a resolution endorsing a program of routine infant circumcision as "an effective public health measure" (Resolution 305-88). Fink's resolution had been rejected by the Scientific Committee of the CMA in 1987, but in 1988 he managed to get it passed by a voice vote of the CMA's House of Delegates without the recommendation of the Scientific Committee. Unlike his success with the AIDS theory, his other invented excuses for circumcision, such as the prevention of group B-streptococcal disease ${ }^{124}$ and "sand balanitis" 125 never succeeded in getting national attention.

Fink's theory that circumcision prevents AIDS has recently been taken up with great vigor by several North American circumcisionists, such as Francis A. Plummer, J. Neil Simonsen, Stephen Moses, Allan R. Ronald, and Joan K. Kreiss. Plummer, especially, has achieved a large measure of popular fame because of his ceaseless advocacy of a campaign of mass involuntary circumcision of the newborn to prevent AIDS.

\subsection{The Future of Involuntary Circumcision}

Since the 1980s, private hospitals have been involved in the business of supplying discarded foreskins to private bio-research laboratories and pharmaceutical companies who require human flesh as raw research material. They also supply foreskins to transnational corporations such as Advanced Tissue Sciences of San Diego, California, ${ }^{126}$ Organogenesis, ${ }^{127}$ and BioSurface Technology, ${ }^{128}$ who have recently emerged to reap new corporate profits from the sale of marketable products made from harvested human foreskins. In 1996 alone, Advanced Tissue Sciences could boast of a healthy $\$ 663.9$ million market capitalization performance. ${ }^{129}$

Despite these market incentives to maintain the practice of involuntary circumcision of the newborn, the circumcision rates in the United States have continued to fall, largely due to the educational outreach of popular and professional anti-circumcision groups. According to the National Center for Health Statistics of the United States Department of Health and Human Services, the rate of neonatal circumcision in the Western United States fell from $64 \%$ in 1979 to $34.2 \%$ in 1994 . As the result of an increase in the circumcision rate in the Midwest, the cumulative national rate, however, only fell from $64.5 \%$ to $62.1 \%$ during the same time period for all hospitals reporting.

In February 1996, a research team at the University of Manitoba, led by Dr. John R. Taylor, published in the British Journal of Urology the most significant anatomical investigation of the foreskin since Winkelmann. ${ }^{130}$ Their paper, "The Prepuce: Specialized Mucosa of the Penis and its Loss to Circumcision," described the structural and functional components of the foreskin and established its rich erogenous innervation and vascularization. Since involuntary circumcision had been initially instituted to ablate these very features, it is not surprising that the medical establishment in the United States has not yet assessed the obvious implications of Taylor's work, even though other organizations have. After extensive review of the medical literature on circumcision - including Taylor's study - both the Australian College of Paediatrics and the Canadian Paediatric Society 
published policy statements on neonatal circumcision in $1996 .{ }^{131-132}$ Both organizations recommended that circumcision of newborns should not be routinely performed, and both statements acknowledged that involuntary circumcision may contravene human rights.

Prominent voices in the world medical community have recently condemned the American practice of involuntary neonatal circumcision as a human rights violation. ${ }^{133-138}$ The consensus among critics is that, regardless of the alleged validity of the arguments used to justify involuntary circumcision of the newborn, involuntary circumcision ipso facto represents an intrusion into the personal lives of individuals and an unwarranted deprivation of personal property. Ultimately, the constitutional conflict between human rights and the American medical establishment's program of involuntary circumcision may be settled by the courts.

\section{CONCLUSIONS}

The historical record makes it clear that American physicians in the late Nineteenth Century institutionalized the sexual mutilation of children as a means of attempting to eradicate childhood sexuality. Physicians performed circumcision on boys to denude, desensitize, and disable the penis to such an extent as to make masturbation theoretically impossible. The clitoridectomy of girls was introduced on the same grounds. While the medical establishment's use of the fear of masturbation to justify mass circumcision has remained fairly constant since the Nineteenth Century, the supplementary and subsequent medical excuses offered to justify the surgical reduction of the genitals of children follow an established pattern: whatever incurable disease happens to be the focus of national attention in any given time period will be the disease that circumcision advocates will use as an excuse for circumcision. In the 1870 s, when epilepsy was the focus of national attention, circumcision advocates claimed that circumcision could cure and prevent epilepsy. In the 1940s, when sexually transmitted diseases were the focus of national attention, circumcision advocates claimed that circumcision could cure and prevent the spread of sexually transmitted diseases. In the 1950s, when cancer was the focus of national attention, circumcision advocates claimed that circumcision could cure and prevent cancer of all sorts - from cancer of the penis, cancer of the tongue, cancer of the prostate, to cancer of the female cervix. Since the late 1980s, when HIV and AIDS have become the focus of national attention, predictably, circumcision advocates have claimed that circumcision can prevent HIV infection.

Ironically, the United States today has both the highest percentage of sexually-active circumcised males in the Western world and the highest rates of genital cancers and sexually transmitted diseases. The paradox implicit in this history is that, even though the program of mass involuntary circumcision has been ineffective as a public health measure to prevent or reduce the ever-increasing rates of genital cancers and sexually transmitted diseases, the American medical establishment has failed to abandon involuntary circumcision in favor of more conservative and more effective public health measures. It has, instead, tried to invent new justifications for circumcision. This unscientific allegiance to a perpetually ineffective, radical, and prejudicial surgical procedure corroborates the hypothesis that there is a deeper, non-rational, psychosexual dynamic behind circumcision advocacy. ${ }^{139}$

The history of the institutionalization of involuntary circumcision of the newborn in the United States demonstrates that society has not always hesitated to pursue what it perceived to be scientific measures at the expense of personal liberties. It is tempting to dis- 
miss circumcision as merely a quaint example of medical quackery pursued by a small handful of zealous physicians. It would be better to remember that, in the name of science, hundreds of millions of American citizens have been subjected to involuntary sexual mutilation. In the face of increasing international condemnation and Constitutional challenges, it is uncertain how much longer the American medical establishment will be able to continue to indulge in the kind of flawed thinking and disregard for human rights that support this activity.

\section{REFERENCES}

1. Szasz TS. Law, Liberty, and Psychiatry. Syracuse: Syracuse University Press. 1989:212.

2. Bichat X. General anatomy, applied to physiology and medicine. 2 vols. Boston: Richardson and Lord. 1822.

3. Broussais F JV. A treatise on physiology applied to psychology. Philadelphia: H.C. Carey and I. Lea. 1826.

4. Deslandes L. De l'onanisme et des autres abus vénériens considérés dans leurs rapports avec la santé. Paris: A. Lelarge. 1835.

5. Lallemand C-F. Des pertes séminales involontaires. Paris: Béchet Jeune, 1836:465-6.

6. Dixon E H. A treatise on diseases of the sexual organs. New York: Burgess, Stringer, 1845:158-165.

7. Editor. Tying the spermatic artery. Boston Medical and Surgical Journal 1842;26:321.

8. Crosby J. Seminal weakness - castration. Boston Medical and Surgical Journal 1843;29:10-1.

9. McMinn SN. Insanity cured by excision of the external organs of generation. Boston Medical and Surgical Journal 1845;32:131-2.

10. Taylor WT. Castration: recovery, followed by phthisis pulmonalis. American Journal of the Medical Sciences 1855;30:85-6.

11. Editor. Castration for masturbation. Medical Record 1894;46:534.

12. Gilbert J A. An unusual case of masturbation. Medical Record 1915;88:608-10.

13. Haynes T. Surgical treatment of hopeless cases of masturbation and nocturnal emissions. Boston Medical and Surgical Journal 1883;109:130.

14. Clark AC, Clark HE. Neurectomy: a preventive of masturbation. Lancet 1899;2:838.

15. M'Cassey JH. Adolescent insanity and masturbation: with exsection of certain nerves supplying the sexual organs as the remedy. Cincinnati Lancet-Clinic 1896;37:341-3.

16. Edson B. Concerning a case for circumcision. Medical World 1902;20:476-7.

17. Ford. Cauterization by injection for spermatorrhœa. Transactions of the American Medical Association $1851 ; 4: 264$.

18. Garwood A. Onanism in a boy seven years old. American Journal of the Medical Sciences 1854;27:553-4.

19. Keating JM. Masturbation. In: Cyclopædia of the Diseases of Children, Medical and Surgical. Vol. III. Philadelphia: J.B. Lippincott, 1890:710.

20. Warren CE. Genocatachresia. St. Louis Medical and Surgical Journal 1892;63:201-15.

21. Kellogg JH. Plain facts for old and young. Burlington, Iowa: I.F. Segner, 1888:295-6.

22. Flood E. An appliance to prevent masturbation. Boston Medical and Surgical Journal 1888;119:34.

23. Editor. Masturbation harness. Medical World 1910;28:133.

24. Editor. Treatment of spermatorrhœa. Boston Medical and Surgical Journal 1861;48:121.

25. Cooper ES. Excision of the clitoris as a cure for masturbation. Boston Medical and Surgical Journal 1862;66:164.

26. Editor. Clitoridectomy. Medical Record 1867;2:71.

27. Hutchinson J. On the influence of circumcision in preventing syphillis. Medical Times and Gazette $1855 ; 2 ; 542$.

28. Hirschfeld J. The jewish circumcision before a medical tribunal. American Medical Monthly 1858;9:272-5.

29. White. Phimosis in new-born children. Boston Medical and Surgical Journal 1861;65:121.

30. Bliss C. Spermatorrhœa - a new method of treatment. Boston Medical and Surgical Journal 1868;77:536-8.

31. Arnold AB. Circumcision. New York Medical Journal 1869;9:514-24.

32. Fishbein M (ed). A History of the American Medical Association, 1847-1847, Philadelphia: W.B. Saunders Co, 1947:636-7. 
33. Sayre LA. Partial paralysis from reflex irritation, caused by congenital phimosis and adherent prepuce. Transactions of the American Medical Association 1870;21:205-11.

34. Sayre LA. Circumcision Versus Epilepsy, Etc. Medical Record 1870;5:233-4.

35. Heckford N. Circumcision as a remedial measure in certain cases of epilepsy, chorea, \&c. Clinical Lectures and Reports by the Medical and Surgical Staff of the London Hospital 1865;2:58-64.

36. Sayre L A. Spinal anæmia with partial paralysis and want of coordination, from irritation of the genital organs. Transactions of the American Medical Association 1875;26:255-74.

37. Jacobi A. On masturbation and hysteria in young children. American Journal of Obstetrics 1876;8:595-606.

38. Moses MJ. The value of circumcision as a hygienic and therapeutic measure. New York Medical Journal 1871;14:368-74.

39. Spratling EJ. Masturbation in the adult. Medical Record 1895;45:442-3.

40. Fisher CE. Circumcision. In: A hand-book on the diseases of children and their homeopathic treatment. Chicago: Medical Century Co, 1895:875.

41. Gentry WD. Nervous derangements produced by sexual irregularities in boys. Medical Current 1890;6:268-74.

42. Editor. The advantages of circumcision. Medical News 1900;77:707-8.

43. Mark EG. Circumcision. American Practitioner and News 1901;31:122-6.

44. Taylor AS. Case of congenital phimosis leading to death at the age of 83 . Lancet 1891;1:1040.

45. Wolbarst AL. Persistent masturbation. Journal of the American Medical Association 1932;90:154-5.

46. Wolbarst AL. Universal circumcision as a sanitary measure. Journal of the American Medical Association 1914;62:92-7.

47. Wolbarst AL. Universal circumcision as a sanitary measure. Journal of the American Medical Association 1914;62:92-7.

48. Wolbarst A L. Does circumcision in infancy protect against disease? Virginia Medical Monthly 1934;60:723-8.

49. Wolbarst AL. Circumcision and penile cancer. Lancet 1932;1:150-3.

50. Bazett HC, McGlone B, Williams RG, Lufkin HM. Sensation: I. depth, distribution and probable identification in the prepuce of sensory end-organs concerned in sensations of temperature and touch; thermometric conductivity. Archives of Neurology and Psychiatry 1932;27:489-517.

51. Diebert GA. The separation of the prepuce in the human penis. Anatomical Record 1933;57:387-99.

52. Hunter RH. Notes on the development of the prepuce. Journal of Anatomy 1935;70:68-75.

53. Guttmacher AF. Should the baby be circumcised? Parents' Magazine 1941;16(9): 26, 76-78.

54. Guttmacher AF. Should the baby be circumcised? Parents' Magazine 1941;16(9): 26, 76-78.

55. Guttmacher AF. Should the baby be circumcised? Parents' Magazine 1941;16(9): 26, 76-78.

56. Ewing J. The causal and formal genesis of cancer. In: Cancer Control. Chicago: The Surgical Publishing Company of Chicago, 1927:168.

57. Ravich A. The relationship of circumcision to cancer of the prostate. Journal of Urology 1942;48:298-9.

58. Editor. Circumcision vs. cancer. Newsweek 1943;21:110-1.

59. Who's Who in America. 42nd edition. 1982-1983. volume 2. Chicago: Marquis Who's Who, 1982/83:2752.

60. Gerber ML. Some practical aspects of circumcision. United States Navy Medical Bulletin 1944;42:1147-9.

61. Heimoff LL. Venereal disease control program. Bulletin of the United States Army Medical Department 1945;3:93-100.

62. Hand EA. Circumcision and venereal disease. Archives of Dermatatology and Syphilography 1949;60:341-6.

63. Editor. Circumcision and VD. Newsweek 1947;30:49.

64. Gairdner D. The fate of the foreskin: a study of circumcision British Medical Journal 1949;2: 1433-7.

65. Miller RL, Synder DC. Immediate circumcision of the newborn male. American Journal of Obstetrics and Gynecology 1953;65:1-11.

66. vide: Obstetrics. ed. J.P. Greenhill. 13 edition. Philadelphia: W.B. Saunders, 1960:1049. and: Eatman NJ, Hellman LM, eds. Williams Obstetrics. 12th edition. New York: Appleton-Century-Crofts, 1961:1101.

67. Ravich A, Ravich RA. Prophylaxis of cancer of the prostate, penis, and cervix by circumcision. New York State Journal of Medicine 1951;51:1519-20.

68. Wynder EL, Cornfield J, Schroff PD, Doraiswami KR. A study of environmental factors in carcinoma of the cervix. American Journal of Obstetrics and Gynecology 1954;68:1016-52.

69. Editor. Circumcision and Cancer. Time 1954;63:96-7.

70. Rathmann WG. Female circumcision, indications and a new technique. GP 1959;20:115-20. 
71. Dietz O, Dougherty EC. Vergleichende Studie zur Frage der Beschneidung in Deutschland und in den Vereinigten Staaten. Deutsche Gesundheitswesen 1957;12:193-6.

72. Kelâmi A. Die sogenannte Gomecotomie als Methode der Wahl für Circumcision. Der Chirurg 1966;37:512-3.

73. Dietz O, Dougherty EC. Vergleichende Studie zur Frage der Beschneidung in Deutschland und in den Vereinigten Staaten. Deutsche Gesundheitswesen 1957;12:193-6.

74. Hofmeister KB. Über erste Erfahrungen mit der routinemäßigen Beschneidung des Neugeborenen in Deutschland und Gedanken zur krebsprophylaxe. Geburtshilfe und Frauenheilkunde 1959;19:20-31.

75. Koester H. Zur Frage der Zirkumzision neugeborener Knaben. Geburtshilfe und Frauenheilkunde 1963;23:934 43 .

76. Dietz O. Erfahrungsbericht über 2800 Zirkumzisionen. Dermatologische Monatsschrift 1970;156:1029-34.

77. Bock JE, Rebbe H. Neonatal Circumcisio. Ugeskrift for Laeger 1973;135:1890-2.

78. Winkelmann RK. The cutaneous innervation of human newborn prepuce. Journal of Investigative Dermatology 1956;26:53-67.

79. Winkelmann RK. The erogenous zones: their nerve supply and its significance. Proceedings of the Staff Meetings of the Mayo Clinic 1959;34:39-47.

80. Gibson EC. Carcinoma of the prostate in jews and circumcised gentiles. British Journal of Urology 1954;26:227-9.

81. Stern E, Neely PM. Cancer of the cervix in reference to circumcision and marital history. Journal of the American Medical Women's Association 1962;17:739-40.

82. Govinda Reddy D, Baruah IJSM. Carcinogenic action of human smegma. Archives of Pathology 1963;75:414-20.

83. Morgan WKC. The rape of the Phallus. Journal of the American Medical Association 1965;193:223-4.

84. Øster J. Further fate of the foreskin: incidence of preputial adhesions, phimosis, and smegma among danish schoolboys. Archives of Disease in Childhood 1968;43:200-3.

85. Preston EN. Whither the foreskin? a consideration of routine neonatal circumcision. Journal of the American Medical Association 1970;213:1853-8.

86. Committee on Fetus and Newborn. Circumcision. In: Hospital Care of Newborn Infants. 5th edition. Evanston, I11: American Academy of Pediatrics, 1971:110.

87. The Boston Children's Medical Center. Pregnancy, Birth and the Newborn Baby. Boston: Delacorte Press, 1971:285.

88. Pomeranz VE, Schultz D. The Mothers' and Fathers' Medical Encyclopedia. Boston: Little, Brown and Company, 1977:109.

89. Livermore B. Like father, like son. Health 1987;19:15.

90. Barton S. Your Child's Health. New York: Bantam Books, 1991:113-8.

91. Masters WH, Johnson VE, Kolodny RC. Human Sexuality. 4th edition. New York: HarperCollins, 1992:58-9.

92. Miller MA, Drakonitides AB, Leavell LC (eds). Kimber-Gray-Stackpole's Anatomy and Physiology 17th edition. New York: Macmillan, 1977:577.

93. Snell RS. Atlas of Clinical Anatomy. Boston: Little, Brown and Company. 1978:136.

94. Campbell MF. The male genital tract and the female urethra. In: Campbell MF, Harrison JH, eds. Urology. vol. 2. Third edition. Philadelphia: W.B. Saunders, 1970:1836.

95. Campbell MF. The male genital tract and the female urethra. In: Campbell MF, Harrison JH, eds. Urology. vol. 2. Third edition. Philadelphia: W.B. Saunders, 1970:1836.

96. Burger R, Guthrie TH. Why Circumcision? Pediatrics. 1974;54:362-4.

97. Wollman L. Female Circumcision. Journal of the American Society of Psychosomatic Dentistry and Medicine 1973;20:130-1.

98. Committee on Fetus and Newborn. Report of the Ad Hoc Task Force on Circumcision. Pediatrics 1975;56:610-1.

99. Editor. Two suits charge circumcision malpractice. Contemporary Ob/Gyn 1986;28(4):150.

100. Editor. Calif. suit raises liability questions in circumcision. Ob.Gyn. News 1986;21(22):1,18 passim.

101. Editor. Two suits charge circumcision malpractice. Contemporary Ob/Gyn 1986;28(4):150.

102. Ginsburg CM, McCracken GH, Jr. Urinary tract infections in young infants. Pediatrics 1982;69:409-12.

103. Wiswell TE, Bass JW. Decreased incidence of urinary tract infections in circumcised male infants. Pediatrics 1985;75:901-3.

104. Fink AJ. In defense of circumcision. Pediatrics 1986;77:265-6.

105. Wiswell TE. Reply to: In defense of circumcision. Pediatrics 1986;77:266-7.

106. McCracken GH Jr. Options in antimicrobial management of urinary tract infections in infants and children. Pediatric Infectious Disease Journal 1989;8:552-5. 
107. Burch FW. Baby Sense. New York: St. Martin's Press, 1991:226.

108. Santesteban A. Child Care for the '90s. Bedford: ABC \& I Press, 1993:18.

109. Dollemore D, Holman M, Kaufman BP, et al. Symptoms: Their Causes \& Cures. Emmaus: Rodale Press, 1994:199.

110. Monmaney R, Raine G. Doubts about circumcision: fewer boys are now cut. Newsweek 1987;109:74.

111. Silberner J, Carey J. Circumcision. U.S. News and World Report 1988;104:68.

112. Rand CS, Emmons CA, Johnson JWC. The effect of an educational intervention on the rate of neonatal circumcision. Obstetrics and Gynecology 1983;62:64-7.

113. Bean GO, Egelhoff C. Neonatal circumcision: when is the decision made? Journal of Family Practice $1984 ; 18: 883-7$

114. Lovell JE, Cox J. Maternal attitudes toward circumcision. Journal of Family Practice 1979;9:811-3.

115. Eriksen NH, Poulsen PN, Friis HM, Vejlsgaard R. Urinary tract infectionsm etiology, diagnosis and treatment with effective antibiotics. Nordisk Medicin 1989;104(2):35-8.

116. Shabad AL, Minakov NK, Mkrtchan GG, et al. The pathogenesis and prevention of urinary tract infection in women. Urologiia I Nefrologiia 1995;(4):8-12.

117. Wiswell TE, Geschke DW. Risks from circumcision during the first month of life compared with those for uncircumcised boys. Pediatrics 1989;83:1011-15.

118. Wiswell TE. Routine neonatal circumcision: a reappraisal. American Family Physician 1990;41:859-63.

119. Ahmann S. Academy holds fast to position on circumcision. Pediatric News 1986;20:38-9.

120. Task Force on Circumcision. Report of the task force on circumcision. Pediatrics 1989;84:388-91.

121. Schoen EJ. Is it time for Europe to reconsider newborn circumcision? Acta Paediatrica Scandinavica 1991;80:573-4.

122. Bollgren I, Winberg J. Reply to: Is it time for Europe to reconsider newborn circumcision? Acta Paediatrica Scandinavica 1991;80:575-7.

123. Fink AJ. A possible explanation for heterosexual male infection with AIDS. New England Journal of Medicine 1986;315:1167.

124. Fink AJ. Is hygiene enough? Circumcision as a possible strategy to prevent neonatal group B streptococcal disease. American Journal of Obstetrics and Gynecology 1988;159:534.

125. Fink AJ. Circumcision and sand. Journal of the Royal Society of Medicine 1991;84:696.

126. Manson B. Forget pork bellies, now it's foreskins. San Diego Reader (May 4, 1995):12, 14 passim.

127. Brewer S. New skin twin life- and look-save. Longevity (September 1992): 18.

128. Rosenberg R. Companies see $\$ 1.5 \mathrm{~b}$ market in replacement skin products. Boston Globe (October 19, 1992): 22-23.

129. Hall CT. Biotech's Big Discovery. San Francisco Chronicle. October 25, 1996:E1, E4.

130. Taylor JR, Lockwood AP, Taylor AJ. The prepuce: specialized mucosa of the penis and its loss to circumcision. British Journal of Urology 1996;77:291-5.

131. Australian College of Paediatrics. Position statement: routine circumcision of normal male infants and boys. Australian College of Paediatrics. 27/05/96.

132. Fetus and Newborn Committee, Canadian Paediatric Society. Clinical practice guidelines: Neonatal circumcision revisited. Canadian Medical Association Journal 1996;154:769-80.

133. Menage J. Male Genital Mutilation. British Medical Journal 1993;307:686.

134. Sorger L. To ACOG: stop circumcisions. OB.GYN.News 1994;(November 1):8.

135. Fleiss PM. Female circumcision. New England Journal of Medicine 1995;322:189.

136. Mullick S. Circumcision. British Medical Journal 1995;310:259.

137. Warren JP, Smith PD, Dalton JD, et al. Circumcision of children. British Medical Journal 1996;312:377.

138. Fleiss PM. More on circumcision. Clinical Pediatrics 1995;34:623-4.

139. Bigelow J. The Joy of Uncircumcising! 2nd edition. Aptos: Hourglass, 1995:89-112. 